\title{
Sustainable Energy for Drying of Cashew Kernels - Experimental Research
}

\author{
Vivekanand B Huddar, Sudershan B Gadwal, M Basavaraj
}

\begin{abstract}
Drying is an important process in food preservation. In cashew processing industries cashew kernels are dried for easy peeling of the thin brownish sticky layer known as testa. For this it is necessary to reduce the average moisture content of $13 \%$ to $5 \%$. Drying is achieved by direct and indirect methods like traditional open sun and using conventional energy through dryers. Due to control of the air properties in indirect drying cashew kernels can be dried at faster rate and can retain their quality. Air flow passages also play an important role in drying process. The objective of the study is to investigate experimentally the energy consumption for drying $1 \mathrm{~kg}$ of cashew kernel using electrically assisted heating and to evaluate the feasibility of active solar air dryer for drying in cashew processing industries.

An electrical heat-assisted dryer (EHD) and an active solar flat plate collector air dryer (ASAD) systems are designed and developed using locally available materials. Both the systems are tested for reduction in moisture content with series of experiments. EHD is tested with three different drying chambers for optimum drying rate. In its final test drying chamber without baffle plates has resulted in reduction in moisture content to required level by $5 \%$ in three hours with drying rate of $2.8 \mathrm{~kg} / \mathrm{h}$ against $6.5 \%$ and $6.8 \%$ in single tray version and four trays with baffle plate version. The drying efficiency of drying chamber is found to be 30.54\%. In ASAD system the experimental results ensure the drying of cashew kernels within stipulated time of 6 hours with drying rate of $1.66 \mathrm{~kg} / \mathrm{h}$ and energy consumption of $255 \mathrm{~kJ}$ against $270 \mathrm{~kJ}$ of electrical heater drying. The drying chamber exhibits an efficiency of 50.89\%. The study suggests that the design is feasible to small, cottage industries for cashew kernel drying. The energy savings up to $3750 \mathrm{~kJ}$ per day for a batch of $15 \mathrm{~kg}$ is possible.
\end{abstract}

Key Words- Cashew kernels, drying, energy, steam, electricity, solar

\section{INTRODUCTION}

Cashew is one of the important nut crop that is grown mainly in the coastal region of the states in India. Its processing provides food, employment and foreign exchange to the nation [1]. Cashew industries are categorized as cottage, small, medium and large scale industries. Dakshina kannada district, in the state of Karnataka, India has more than 350 cashew processing industries. All these industries use wood, kerosene and electricity for their thermal energy needs. Drying is one of the important processes in cashew processing. It is basically used to remove high moisture content of the cashew kernels

Revised Manuscript Received on April 12, 2019.

Dr. Vivekanand B Huddar, Department of Mechanical Engineering, Bearys Institute of Technology, Mangalore, Karnataka, India. (E-mail: vbhuddar2017@gmail.com)

Dr. Sudershan B Gadwal, Department of Mechanical Engineering, A G Patil Institute of Technology, Sholapur, Maharashtra, India. (E-mail: gadwalsb@gmail.com)

Dr. M Basavaraj, Department of Mechanical Engineering, Bearys Institute of Technology, Mangalore, Karnataka, India. (E-mail: drmbraja@gmail.com) for its safe preservation and ease of peeling process. Present methods of drying the cashew kernels use conventional fuels like kerosene, diesel, electricity and wood. Thermal energy produced by burning these fuels is used to generate steam to heat the air that dries the cashew kernels in borma. Conventional fuels used for burning in boilers are costly, depleting in nature, pollutes the environment and also responsible for global warming [2, 22]. Energy is the most important, critical and vital component in these rural agro industries for development, employment generation and economic growth. In India, variety of raw materials (local and imported), location (rural or urban), technological mechanization (cottage, mini or major) and availability of secured energy supply decide the different unit operation or methodologies employed by cashew processing industries The most energy and time intensive unit operations in cashew processing are drying of raw cashew nuts in open sun, boiling of raw cashew nuts in steam and kernel drying using electrical energy. Small scale industries engaged in batch production of $15 \mathrm{~kg} / \mathrm{batch}, 30 \mathrm{~kg} / \mathrm{batch} \& 60 \mathrm{~kg} / \mathrm{batch}$ have electrical energy consumption of $763.58,696.39 \&$ $504.28 \mathrm{MJ} / 1000 \mathrm{~kg}$ of raw cashew nut seeds [3]. After removing the hard outer shell the kernel is the edible part that is the final product. This cashew kernel contains a brownish cover known as 'testa' sticked to the edible kernel. To remove testa and also control the moisture content kernels are dried in perforated trays by exposing to prolonged and controlled hot air in a closed chamber at 65 $70{ }^{\circ} \mathrm{C}$ for $6-8$ hours. About $5-8 \%$ of moisture used to be removed from the kernels in the process [4]. The energy consumption for cashew processing to produce the same quantity of similar products revealed wide variations in energy intensity, ranging from 4.43 to $8.66 \mathrm{~kg}$ of fuel wood per kilogram of kernel. This variation in energy consumption reveals the scope for energy conservation of the order of 30-48\% [5]. Electrical dryers have shown thermal efficiencies as high as $37 \%$ and $69.5 \%$ in case of ginger and banana drying respectively [6-7 \& 23].

The annual global solar radiation in India varies from 1600 to $2200 \mathrm{kWh} / \mathrm{m}^{2}$. Karnataka receives a global solar radiation in the range of $5.1-6.4 \mathrm{kWh} / \mathrm{m}^{2}$ during summer, 3.5-5.3 $\mathrm{kWh} / \mathrm{m}^{2}$ during monsoon and $3.8-5.9 \mathrm{kWh} / \mathrm{m}^{2}$ in winter. The global solar radiation in Dakshina Kannada has $6.16,3.89$ and $5.21 \mathrm{kWh} / \mathrm{m}^{2}$ respectively during summer (February - May), monsoon (June -September) and winter (October - January). The study identifies that coastal parts of Karnataka with higher global radiation is ideally suited for harvesting solar energy [8]. In large and medium scale 
the processing of cashew is year round as they import the raw cashew nuts from abroad like Vietnam, Ghana in Africa. Small and cottage industries rely on the local supply and the processing is mostly during the summer between February to May. Solar air heating systems have been used for drying several agricultural and food products [9]. These can be utilized to replace present conventional systems in cashew processing industries. Several types of single pass solar air dryers have been designed and tested for their performance evaluation like efficiency; operating temperature and suitability for different applications like drying various agricultural products, space heating etc. [1011]. In all the cases the main idea is to use the heat energy collected during the day and use during day/night. Various types of double pass solar collectors with fins, thermal energy storage and reflectors have been introduced to increase the thermal efficiencies. In these cases the efficiencies are increased for thermal storage up to $10 \%$ and for those with booster reflectors $20-30 \%$. When compared to single pass collectors the efficiency is greater by $30-40 \%$ [12-19]. Multi pass solar collectors show a better performance over single and double solar collectors [20, $21 \& 24]$. Thus it is planned to design and develop a triple pass solar collector. For bulk quantities greenhouse dryer are preferred which are operated both in active and passive modes [25].

The present work aims at investigating experimentally the energy requirement for drying $1 \mathrm{~kg}$ of cashew kernel with attaining end quality in experiments 1 \& 2. Experiment 1 uses electrical (conventional) energy whereas experiment 2 uses solar (non-conventional) energy by replacing the electrical heater only by a flat plate collector. Both these are scaled down models to check the energy consumption along with the performance of dryer and feasibility in introducing active solar hot air dryer in the cashew processing industry.

\section{EXPERIMENTATION - DESIGN, CONSTRUCTION AND TESTING}

Experiments are conducted to test the developed experimental setup for drying cashew kernel using three different drying chambers. In each test one $\mathrm{kg}$ of drying material is brought from nearby cashew processing industry that is ready to send to the drying section after shell cutting process. Material is loaded in the trays after weighing in a precision weighing scale. Series of tests are conducted on each dryer. First two dryers have duration of four hours while last one has three hours in achieving the expected results. End results in both the systems are checked with weight reduction technic and measurement of moisture content using digital moisture content test instrument for cross verification. For weight reduction technic, a thumb rule is followed that is $1000 \mathrm{~kg}$ load has to be reduced to $940 \mathrm{~kg}$ after drying. That is there should be a weight reduction of $6 \%$ to have a moisture content of $5 \%$.

\section{Experiment 1: EHD System}

\section{Dryer with single and four tray}

Final tests are conducted on 21 March 2015 and 28 April 2015 respectively at Udupi city, Karnataka, India. The experimental setups are tested initially on no load run and

checked for parameters like temperatures at different points, relative humidity, and velocity of air.

The setup is allowed to run for one hour in idle condition to reach steady state. In single tray setup the drying chamber is designed for $5 \mathrm{~kg}$ but for test purpose equipped with only middle tray with loading of $1000 \mathrm{~g}$. The mass of the cashew kernels after drying is found to be $955 \mathrm{~g}$. There is a reduction in weight of $45 \mathrm{~g}$ against expected $60 \mathrm{~g}$. The analysis of the experiment shows an uneven distribution of heat in the drying chamber. In four tray setup a small cabinet type drying chamber each tray was loaded with $250 \mathrm{~g}$. Baffle plates are included in the design to retain the heat and also acts as a guide to direct the working fluid through all the four trays. The inlet is given at the top and exit at the bottom. Hot air flows through trays counting 1 to 4 from top to bottom. Experiment resulted in a weight reduction of $35 \mathrm{~g}$ against $60 \mathrm{~g}$ required. The final weight of the dried cashew kernels is found to be $965 \mathrm{~g}$. This is again because of improper distribution of the heat to the product in drying chamber. There was no much of improvement with perforated baffle plates. The schematic view of the experimental setup is shown in figure 1.

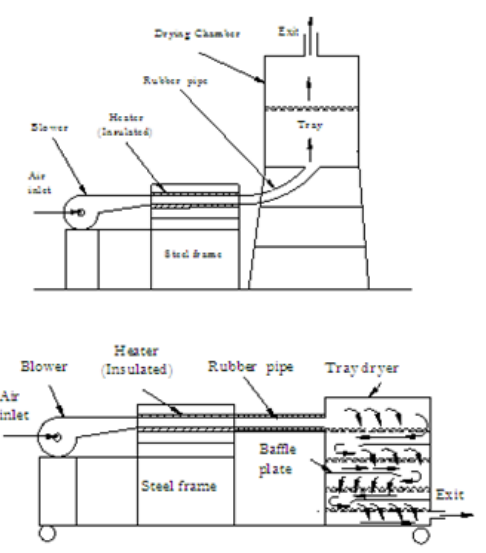

Figure 1: Schematic view of EHD system with single \& four tray drying chamber

Dryer with four trays but without baffle plates

Keeping all other conditions same third experiment is conducted on 29 April 2015. The baffle plates in the drying chamber are removed and only four trays are retained at equidistance. Fresh $1000 \mathrm{~g}$ of cashew is loaded for testing. Experimental results of three hours duration show a final weight as $932 \mathrm{~g}$ which is $6.2 \%$ weight reduction. The moisture content is found to be $<5 \%$. The dried cashew kernels are given for hand peeling in the processing industry for cross verification. All the kernels are peeled, found to have good colour and better taste.

\section{Experiment 2: Active Solar Air Dryer [ASAD] System}

A multi pass solar flat plate collector with $\mathrm{V}$ groove mild steel absorber plate with fins on alternate groves to increase the heat transfer area was designed and constructed. It has dimensions of $1 \mathrm{~m} \times 2 \mathrm{~m}$ with an area of $2 \mathrm{~m}^{2}$. The sectional details and arrangement of the system is shown in the figure 2. 


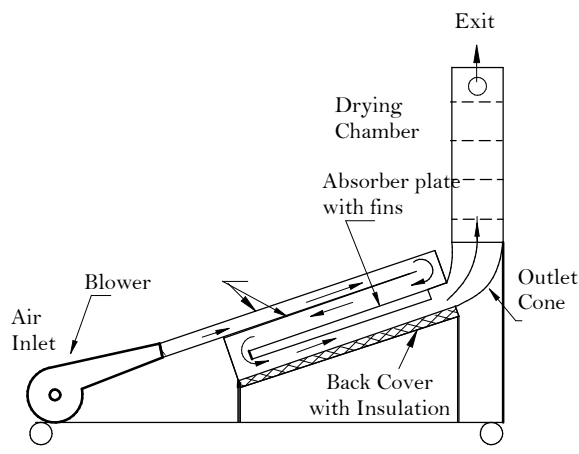

Figure 2: Sectional view of ASAD setup

All the components of the earlier setup are maintained same except the inlet to dryer. Inlet and outlet cones are provided to connect the dryer to blower and drying chamber respectively. The cones are facilitated with ribs to provide uniform distribution of air throughout the width of dryer. All the joints were made leak proof and are wrapped with asbestos to make it adiabatic. In this mode of experiment, only heater was replaced with multi pass solar flat plate collector to maintain the similarity in end conditions. The complete setup was mounted on a steel frame and was kept facing due south on a selected plain area during experimentation. The estimated efficiency of the collector is found to be $71.8 \%$. The results of analysis of solar flat plate collector are shown in table 1.

\section{TABLE I: ANALYSIS OF SOLAR FLAT PLATE COLLECTOR}

\begin{tabular}{|l|l|l|l|}
\hline $\begin{array}{l}\text { S } \\
\text { N }\end{array}$ & Description & Symbol & Value \\
\hline 1 & Input energy to Solar FPC & $Q_{I}$ & $4717 \mathrm{~kJ}$ \\
\hline 2 & Energy received by FPC & $Q_{\text {gain }}$ & $3448 \mathrm{~kJ}$ \\
\hline 3 & Energy Losses in FPC & $Q_{\text {loss }}$ & $2476 \mathrm{~kJ}$ \\
\hline 4 & $\begin{array}{l}\text { Useful energy extracted by } \\
\text { FPC }\end{array}$ & $Q_{u}$ & $541 \mathrm{~kJ}$ \\
\hline 5 & Efficiency of solar FPC & $\eta_{F P C}$ & $71.8 \%$ \\
\hline 6 & $\begin{array}{l}\text { Energy Loss in duct - FPC } \\
\text { and DC }\end{array}$ & $Q_{\text {exit cone }}$ & $48 \mathrm{~kJ}$ \\
\hline
\end{tabular}

The energy analysis in the form of block diagram, actual energy analysis and pictorial view of the experimental setup of both EHD and ASAD systems along with instrumentation used in the EHD and ASAD systems are shown in the figure 3 , Table 2 and figure 4 respectively.

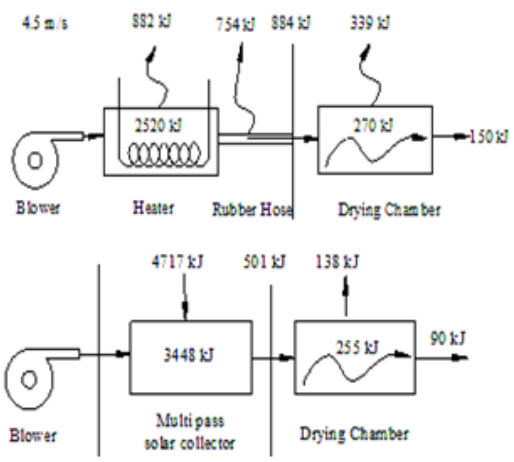

Figure 3: Block diagram of energy consumption in EHD and ASAD Systems
TABLE 2: ANALYSIS OF DRYING CHAMBER EHD \& ASAD SYSTEMS- ENERGY BALANCE

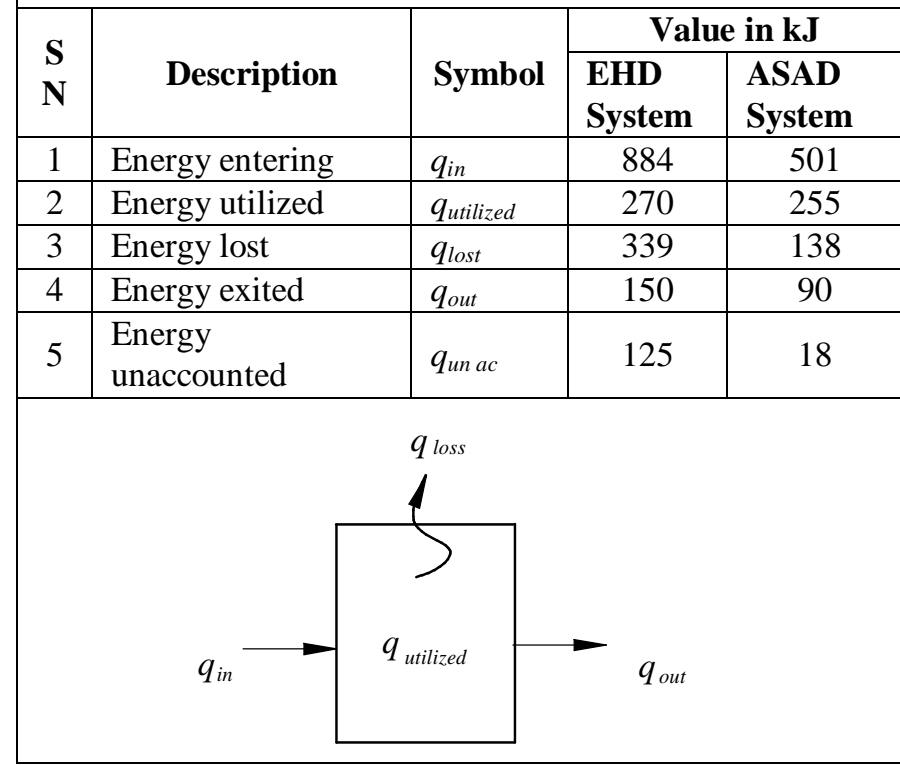
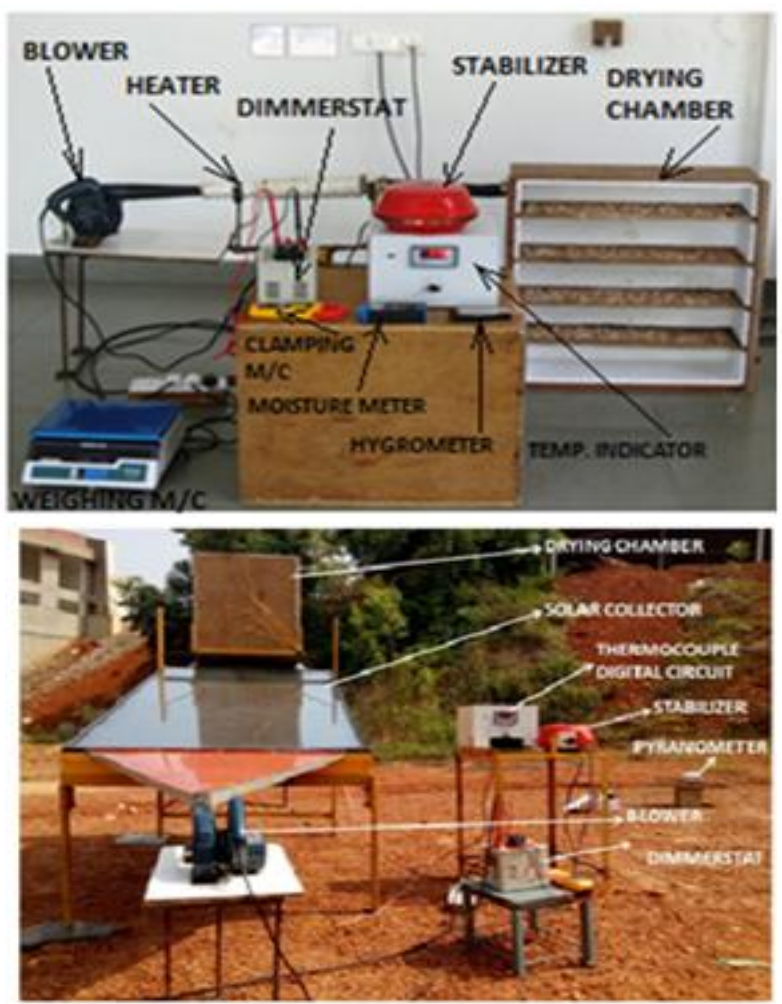

Figure 4: Pictorial view of the drying chamber with four trays and solar flat plate collector

\section{RESULTS \& DISCUSSION}

Dying is combined heat and mass transfer activity. Heatassisted dryers create warm air flow inside the dryer to speed up drying. The majority of energy used in heated air dryers is actually used to heat the fluid-air. Electricity for moving air is only a small fraction of the air heating costs, which depend on the initial and final moisture contents of the product.

Blue Eyes Intelligence Engineering \& Sciences Publication 

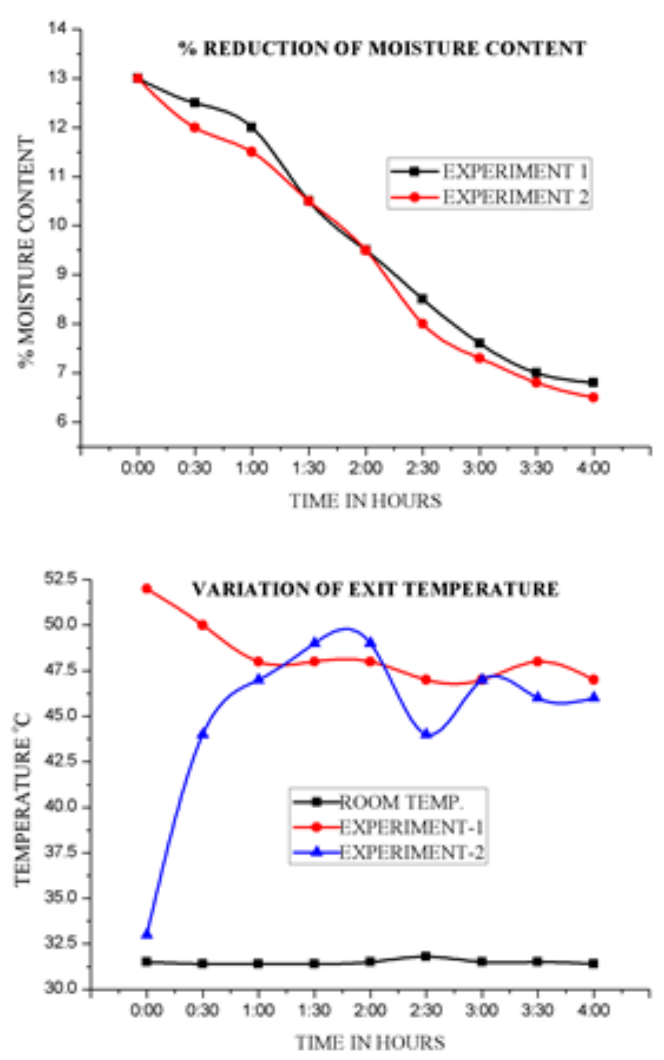

Figure 5: Variation of exit temperature and moisture content against hours of Expt. 1 \& 2

Experimental results of EHD \& ASAD systems are discussed below. Figure 5 shows the variation of exit temperature and moisture content of the EHD system. It is observed that the moisture content curves vary between 13 to $6.8 \& 6.5 \%$ respectively with variation of exit temperature is in the range of 47 to $52{ }^{\circ} \mathrm{C}$ and 33 to $46{ }^{\circ} \mathrm{C}$ respectively. The average temperature for these being $48 \&$ $45{ }^{\circ} \mathrm{C}$ indicates lot of energy is going out of the drying chamber without use. Hence the required objective of reducing moisture content is not achieved.

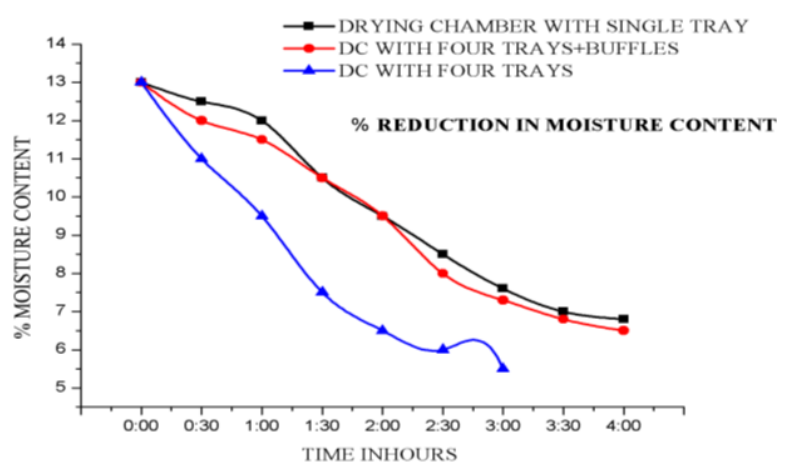

Figure 6: Time Vs. Variation of moisture content against time during experimental trials

Figure 6 shows variation of moisture content of the product for all the three variations of EHD system. In variation $1 \& 2$ with single tray DC and four tray DC with baffle plates the final moisture content found is 6.8 and 6.5 $\%$ respectively for test duration of four hours. At this level it is difficult to peel of the testa in peeling section. In third experiment a safe level of $<5 \%$ is achieved in test duration of three hours with better drying rate of $2.8 \mathrm{~kg} / \mathrm{h}$ and drying efficiency of $30.54 \%$.

\section{Active Solar Air Dryer [ASAD] System:}

The experiment is conducted on a clear sunny day. The global radiation obtained on the day varies from 419 to 764 $\mathrm{W} / \mathrm{m}^{2}$ during the experimentation hours of 10.00 am to 4.00 $\mathrm{pm}$. The relative humidity show a quite minimum value during the mid of the day whereas global radiation was found maximum. The root mean square value of same was found to be $59.65 \%$. The reasonable temperatures achieved in all the four trays ranging from $35^{\circ} \mathrm{C}$ to $58^{\circ} \mathrm{C}$ dried the cashew kernels to the required moisture content. Thus the half hourly variation of hot air temperature on four trays is much higher than the ambient temperature during most of the hours of the experimentation on the day and indicates a better performance of the system. The dried cashew kernels are tested for peeling process and quality. All of the cashews are peeled off and their taste and appearance found good. Table 3 shows important results of the experimentation and figure 7 provides variation of relative humidity and solar global radiation against time of the day.

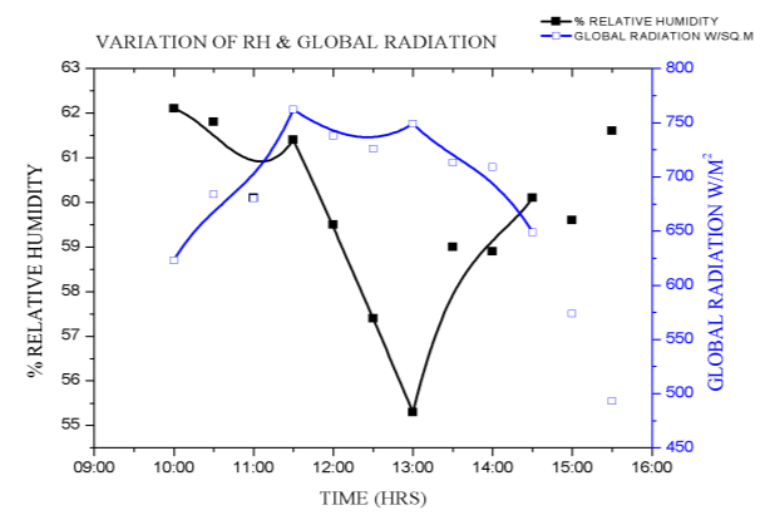

Figure 7: Variation of relative humidity and solar global radiation against time of the day

TABLE III: IMPORTANT RESULTS OF EXPERIMENTATION

\begin{tabular}{|c|l|l|l|}
\hline $\mathbf{N}$ & \multicolumn{1}{|c|}{ Description } & \multicolumn{1}{c|}{ Symbol } & \multicolumn{1}{c|}{ Value } \\
\hline & $\begin{array}{l}\text { Solar Flat Plate } \\
\text { Collector Input energy }\end{array}$ & $Q_{I}$ & $4717 \mathrm{~kJ}$ \\
\hline 2 & Energy received & $Q_{\text {gain }}$ & $3448 \mathrm{~kJ}$ \\
\hline 3 & Efficiency & $\eta_{F P C}$ & $71.8 \%$ \\
\hline 4 & $\begin{array}{l}\text { Drying Chamber - } \\
\text { Energy entering }\end{array}$ & $q_{\text {in }}$ & $501 \mathrm{~kJ}$ \\
\hline 5 & Energy utilized & $q_{\text {utilized }}$ & $255 \mathrm{~kJ}$ \\
\hline 6 & Efficiency & $\eta_{d c}$ & $50.9 \%$ \\
\hline 7 & $\begin{array}{l}\text { System ASAD - } \\
\text { Instantaneous efficiency }\end{array}$ & $\eta_{i}$ & $26.25 \%$ \\
\hline 8 & Drying Rate & $D R$ & $1.66 \mathrm{~kg} / \mathrm{h}$ \\
\hline
\end{tabular}

Published By: 


\section{Drying Chamber Trays:}

Figure 8 shows the comparison of drying curves of cashew kernels before and after drying in trays 1 to 4 respectively for the selected samples in both electrical and solar mode of drying. A variation in curves for 'before drying' can be observed in all the four graphs as the samples for the two experiments conducted are on different dates and are collected from different sources.

Tray 1 shows a close agreement between the moisture content profiles of before and after drying process of conventional and solar drying methods. The percentage of moisture content in the tray of the solar setup varies from 3 to $6 \%$. In tray 2 , the variations of the before and after drying curve profiles of conventional and solar are linear based on the initial and final moisture contents of the cashew kernels. Even though a large variation was found with curve of after drying profile of solar setup the variation is within the range except for selected sample 4 . This variation was because of the hot pockets in the convection current within the dryer. In tray 3 even though there is greater variation in initial moisture contents, final moisture contents in both the cases show a close approximation. However, the range of moisture content lays well within the limits 3 to $6 \%$. Similar conditions were found in tray 4. Unlike conventional the final results of the solar setup are found well within the acceptable range of 3 to $6 \%$ final moisture content.

In all the four trays the hourly variation of the drying chamber temperature is much higher than the ambient temperature during the most part of the experimental period. A uniform temperature of $40-45^{\circ} \mathrm{C}$ was achieved in all the four trays throughout the experimentation providing constant heat to the product as well retain its nutritional values and appearance.

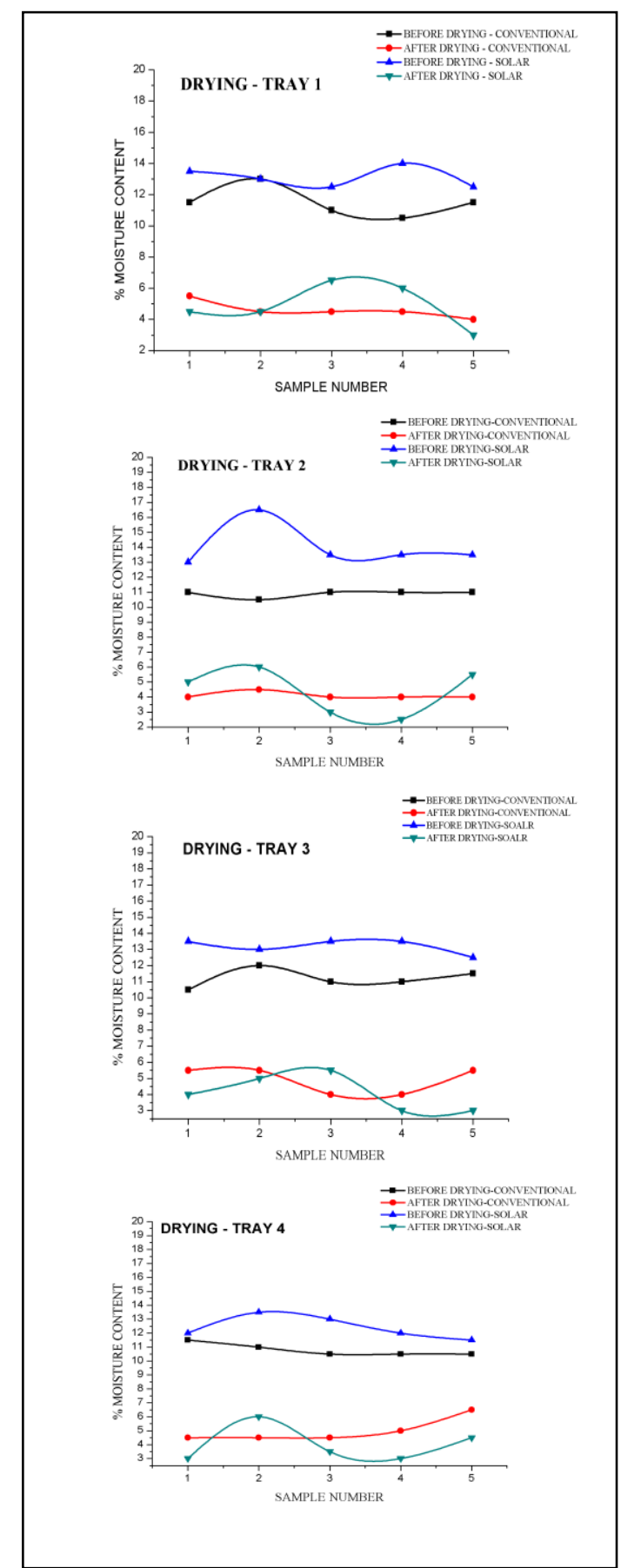

\section{Figure 8: Comparison of drying curves of cashew kernels before and after drying in trays 1 to 4 respectively for the selected samples in both electrical and solar mode of drying}

\section{CONCLUSIONS}

Based on the experimental results obtained in EHD and ASAD systems following conclusions are drawn.

The drying is the one of the activities where the major energy is consumed in the processing of cashews. Proper design and functioning of the drying chamber is important to have correct drying and at optimum time. 
1. In the first experiment, even though the temperature of the air is adequate because of low velocity the drying rate is found less. In the second experiment, temperature of the air is maintained with increase in velocity. The improper passage of the air in the drying chamber by inclusion of the baffle plates affected the drying process. In the third experiment, both the parameters velocity and flow passage are maintained and proper air flow helps in drying process. The objective of reduction in the moisture content for $5 \%$ is achieved in three hours.

2. The drying rate is optimized to $2.8 \mathrm{~kg} / \mathrm{h}$ resulting in energy saving compared to other two experiments with drying chamber efficiency $30.54 \%$ in EHD system.

3. The energy consumption to dry one $\mathrm{kg}$ of cashew kernel is $255 \mathrm{~kJ} / \mathrm{kg}$ against $270 \mathrm{~kJ} / \mathrm{kg}$ for $\mathrm{EHD}$ system indicates that the developed ASAD setup has consumed lesser energy comparatively.

4. The difference in variation of energy consumption with two systems is because of the temperatures during sensible heat addition to raise the temperature of working fluid-air.

5. The system exhibited sufficient ability to dry cashew kernels at a reasonable time of six hours with good appearance and quality ensuring its feasibility to introduce.

6. It is observed from the experiment that suitable environment is available for drying cashew kernels to achieve a safe moisture content of $5 \%$.

7. Solar flat plate collector and the drying chamber have shown efficiency of $71.8 \& 50.9$ respectively.

8. The system provides an energy savings up to $3750 \mathrm{~kJ}$ per day for a batch of $15 \mathrm{~kg}$.

\section{REFERENCES}

1. Atul Mohod et al, (2010), Elucidation of unit operations and energy consumption pattern in small scale cashew nut processing mills, Elseveer, Journal of Food Engineering 99 184-189

2. Dr. T V Ramachandra, CES technical report 88, (June 2000), Energy Alternatives: Renewable energy and energy conservation technologies, page \# 25

3. Atul Mohad et al, (2011), Quantification of energy consumption for cashew nut processing operations, International Journal of Sustainable Energy, Vol. 30, S11-23

4. Energy options for small scale cashew industries

5. K. Gyanwali et al, "A study on electric dryer for cash crops drying as an end-use promotion of micro hydro power in nepal \& it's comparative analysis with biomass based drying system", Journal of science and engineering, Vol.10, No.I, November, 2014

6. André Guimarães Ferreira et al, "Technical feasibility assessment of an electrical dryer for banana drying", 22nd International Congress of Mechanical Engineering, November 3-7, 2013

7. T V Ramachandra, (2007), Solar energy potential assessment using GIS, Energy Education Science and Technology, Volume (issue) 18(2): 101-114

8. C.L. Hii et al, (2012), Solar Drying: Fundamentals, Applications and Innovations, ISBN: 978-981-07-3336-0, page \# $25-30$

9. Ali Zomorodian and Maryam Zamanian, (2012), Designing and Evaluating an Innovative Solar Air Collector with
Transpired Absorber and Cover, Renewable Energy, Volume 2012, Article ID 282538, 5 pages

10. A.Anuradha \& Dr (Mrs) Rachel Oommen, (June-2013), Fabrication and Performance evaluation of a v-groove solar air heater, International Journal of Scientific \& Engineering Research, Volume 4, Issue 6, 2072 ISSN 2229-5518

11. Abhishek Saxena \& Harish Yadav, (Jan. 2013), Thermal Performance of a Hybrid Solar Air Heater, MIT International Journal of Mechanical Engineering, Vol. 3, No. 1, pp. 57-62, ISSN No. 2230-7680 @ MIT Publications

12. M. Joseph Stalin \& P. Barath, (Mar 2013), Effective Utilization of Solar Energy in Air Dryer, International Journal of Mechanical and Production, Engineering Research and Development (IJMPERD), ISSN 2249-6890, Vol. 3, Issue 1, 133-142

13. Salwa et al, (2013), Performance of a new solar air heater with packed bed latent storage energy for nocturnal use, Applied Energy 110, 267-275

14. Bashria Abdrub et al, Performance Analysis for V-Groove Absorber, Sci. Technol. 14(1):39-52

15. Ahmad Fudholi et al, Performance of Finned Double-Pass Solar Air Collector, Recent Advances in Fluid Mechanics, Heat \& Mass Transfer and Biology, ISBN: 978-1-61804-0657

16. Jose E. Quiñonez et al, (November 2012), Development and Experimental Evaluation of a Vertical Solar Air Collector for Heating of Buildings, PLEA 2012 - 28th Conference, Opportunities, Limits \& Needs Towards an environmentally responsible architecture Lima, Perú 7-9

17. K. Sopian K et al, (2009), Evaluation of thermal efficiency of double-pass solar collector with porous-nonporous media, Renewable Energy 34, 640-645

18. S.S.Kashinath \& K. Kalidasa M, (2013), Experimental Study of The Double-Pass Solar Air Heater with Thermal Energy Storage, Journal of King Saud University-Engineering Sciences 25, 135-140

19. Hiroshi Tanaka, (2011), Theoretical analysis of solar thermal collector with a flat plate bottom booster reflector, Energy Science \& Technology, Vol 2, No. 2, pp26-34

20. P. Velmurgan \& R Kalaivanan, "Thermal performance studies on multi pass flat plate solar air heater with longitudinal fins: An analytical approach", Springer, 2015,40, 1141-1150

21. G.O.I. Ezeike, Development and performance of a triple-pass solar collector and dryer system,ELESEVIER, Energy in agriculture, Vol.5, Issue 1, 1986, 1-20.

22. Vivekanand B. Huddar \& Dr. M. A. Kamoji, An optimization model for energy saving opportunities in cashew processing industry, International Journal of Research in Mechanical Engineering \& Technology, Vol. 5, Issue 1, Spl - 1 November 2014 - April 2015

23. Vivekanand B. Huddar \& Dr. M. A. Kamoji, Experimental investigations on electrical heat assisted drying of cashew kernels, IOP (Institute of Physics) conference series, Material science and engineering journal. (Scopus Indexed) doi:10.1088/1757-899X/376/1/012093.

24. Vivekanand B. Huddar \& Dr. M. A. Kamoji, Feasibility of introducing solar air-dryer for drying process in cashew industries, International Journal of Recent Technology and Engineering, April 2019.

25. Vivekanand B. Huddar \& Dr. M. A. Kamoji, Experimental investigation on performance of small passive solar greenhouse dryer for cashew kernel drying, AIP Conference Proceedings 2080, 030001 (2019); doi.org/10.1063/1.5092904 